\title{
BIM-based facilities information: streamlining the information exchange process
}

\author{
Sandra Matarneh, Mark Danso-Amoako, Salam Al-Bizri and Mark Gaterell \\ Civil Engineering and Surveying, \\ University of Portsmouth Faculty of Technology, Portsmouth, UK, and \\ Rana Matarneh \\ Architecture School, Al-Ahliyya Amman University, Amman, Jordan
}

\begin{abstract}
Purpose - The purpose of this study is to address challenges in the current information exchange process between building information modelling (BIM) and facilities management (FM) systems and to propose a workable solution. This study's objective is to identify the information exchange requirements and to develop methods for seamless information flow between building information models and FM systems.

Design/methodology/approach - Data collection and analysis was based on an extensive literature review of similar studies followed by a questionnaire survey with a total of 112 participants and 2 focus groups with a total of 12 participants to validate the conceptual framework. The outputs of the survey analysis formed the background of the proposed framework to streamline information exchange process between building information models and FM systems.

Findings - The study findings form a foundation for enabling the integration of various data sources including building information models. Such integrated platforms will enable automated information exchange between the various data sources and FM systems. The study also provides key information requirements sources to complement the existing construction operations building information exchange information and to support standardization for information exchange process.
\end{abstract}

Originality/value - The contribution of this study is the identification of information exchange requirements and sources to enable seamless information flow between BIM and FM systems. The study findings will also lay the basis for research studies using the developed framework context to enable the identification of specific data outputs for FM systems inputs. 
Keywords Interoperability, Information exchange, Building information modelling (BIM), Construction operations building information exchange (COBie), Facilities information systems, Facilities management (FM), Interoperability, Industry foundation classes (IFC)

Paper type: Conceptual paper

\section{Introduction}

During the operations and maintenance phase, facilities management (FM) teams often spend a considerable amount of time and effort collecting information in the form of electronic data and hardcopy documents. Employees engage in constant redundant activity searching for, sorting, validating and recreating information (Brodt, 2013). The National Institute of Standards and Technology (NIST) reported that two-thirds of the projected \$15.8bn lost in the USA capital facilities industry was associated with inadequate interoperability during the operations and maintenance $(\mathrm{O} \& \mathrm{M})$ phase. Losses because of poor interoperability resulted from the expenses of manual data re-entry, data verification, redundancy and wasted labor time looking for data that were often unavailable. Minimizing the effects of interoperability problems requires a seamless electronic data exchange to provide FM teams with a comprehensive and accurate database (Gallaher et al., 2004).

Building information modelling (BIM) can provide a data conduit and repository to support O\&M activities (Sabol, 2013), but it is not sufficient in itself to mitigate the costs of faulty interoperability. There is a need for a common data model or schema for BIM data models to be interoperable with FM systems. PAS1192-3:2014 specifies an information management methodology for the O\&M phase of building assets based on open BIM standards - Industry Foundation Classes (IFC) and Construction Operations Building information exchange (COBie) (BSI 2014a). The PAS1192-3:2014 focuses on the early engagement of FM team to ensure that facilities information requirements are considered from the early stages of the construction projects (BSI 2014a). Information in BIM models should reflect the Employer Information Requirements (EIR) which should be specified in the Asset Information Requirements (AIR) so that at the handover stage, handover data can be an output for FM systems input (BSI 2013). Several standardization efforts are proposing the use of BIM capabilities as a data conduit to support facilities information management such as BS 1192-4:2014 which supports facilities information exchange requirements using construction operations building information exchange (COBie) (BSI 2014 b). COBie works like a filter that selects and arranges only necessary non-geometric information for the management and operation of a building into ten main categories: facility, floor, space, zone, type, components, system, spares, job and resources. COBie is a repetitive process, with four defined data drops taking place at crucial stages of the project life cycle to capture the required and available data for FM (East and Carrasquillo-Mangual, 2013). 
There are various ways that COBie information can be exported from BIM models. Regardless of which tool is used to compile and create the COBie spreadsheet, one of the following principles will be adopted:

- COBie data are exported directly from BIM models using third-party add-in applications (such as the Autodesk COBie Extension for Revit).

- IFC data can be exported from BIM models and the COBie spreadsheet can be extracted as a "View Definition" from this data set; in many cases, the IFC format would be an acceptable method providing the COBie data (East and Carrasquillo- Mangual, 2013).

However, the BIM authoring products that export COBie data automatically and generate COBie spreadsheet are inherently limited in generating all the FM-required data, as a manual data entry is still required to enter data such as periodic preventive maintenance (PPM) schedules (Lee et al., 2013). Building such a database via manual data entry from individual stakeholders is costly and rarely achievable (Brodt, 2013). There needs to be a solution for the easy transfer of facilitymaintained asset data into FM systems. In this study, we aimed to develop a conceptual framework for seamless data exchange between BIM and FM systems by incorporating data from BIM models and from various other data sources to generate a rich, interoperable data format that includes the required FM information.

\section{Research background and related studies}

There is no doubt that the proliferation of advanced computerization is yielding business benefits that are valued by the construction industry. Automation within the BIM-FM integration process will revolutionize how buildings are conceived, developed, built and used. However, there are some challenges of integrating BIM in FM practice that require innovative solutions to transform industry practice (Pärn et al., 2017). The opportunity to enhance facilities information management performance using BIM-rich semantic data is lost because of the existing gaps in software interoperability when transitioning data between as-built BIMand FM systems (Pärn et al., 2017). Realizing BIM's capabilities to support FM activities needs extensive software development to facilitate information exchanging between as-built BIM and existing FM systems (Gao and Pishdad-Bozorgi, 2019).

The inherent power of BIM for FM is mainly associated with streamlining information flow between the project stakeholders during the facility lifecycle and facilitating information handover to FM teams (Matarneha et al., 2018; Reza Hosseini et al., 2018). Yet information flow among project stakeholders is neither automated nor seamless. There are still technical issues to be overcome: mainly identifying the required FM information for data exchange purposes and boosting interoperability between BIM and FM systems (Gao and Pishdad-Bozorgi, 2019; Matarneha et al., 2019; Yalcinkaya and Singh, 2019). Although standard data formats are capable 
of exchanging data between different platforms, particularly IFC and COBie schemas, the data exchange process between BIM and FM systems using open standard data formats is not a straightforward process. For example, the integration between BIM and the computer-aided facility management (CAFM) system has been actively criticized for inadequate data interoperability, particularly the inability to transfer semantic FM information properly (BIFM, 2013).

Studies in this research have shown that many comprehensive systems are developed on the foundation of BIM-based facility database, which allows new functionalities such as visualization and data accessibility to perform various analysis and automate some of the O\&M activities (Gao and Pishdad-Bozorgi, 2019). Yet studies that investigate interoperability solutions between BIM and FM systems are scarce (Reza Hosseini et al., 2018; Gao and Pishdad-Bozorgi, 2019; Matarneha et al., 2019). There is a need to understand the underlying information exchange requirements between BIM and FM systems and standardizing a process for information exchange between BIM and FM systems (Kasprzak and Dubler, 2012; Nicał and Wody $\square$ nskib, 2016; Pärn et al., 2017; Gao and Pishdad-Bozorgi, 2019; Matarneha et al., 2019).

\subsection{Identifying the information required for facilities management}

Today's facilities are highly sophisticated and the need for available, reliable information for O\&M activities is vital (Jordani, 2010). The key challenge for an FM team is to obtain accurate, real-time data in a complete database to perform daily activities and to provide senior management with reliable information for decision-making (Atkin and Brooks, 2009; Pärn et al., 2017). Currently, there are a variety of technology platforms, data repositories and databases such as computerized maintenance management systems (CMMS) that are used for these purposes in various facilities. In a typical FM practice, data are extracted from hardcopy construction documents or electronic data such as .pdf files and is re-entered manually into a CAFM/CMMS system (Teicholz, 2013). The concept of extending BIM implementation through the O\&M phase is simply to reduce the O\&M costs and reap the real benefits of BIM capabilities. However, in most current practices where BIM is implemented to support FM operations, FM teams do not use BIM models because they either do not include the required FM data or the models contain a huge amount of superfluous data which makes the data exchange process tedious and overwhelming (Sabol, 2013). Hjelseth (2010) stated that "an overload of information causes a lack of purpose, and therefore what could be information, is simply unused data". This necessitates a pragmatic approach to identify the required information and to collect it from the project stakeholders in a way that FMteams can use efficiently.

Recent studies have focused on very specific information requirements by identifying the required information of: healthcare facilities (Lucas and Thabet, 2013; Irizarry, 2014), HVAC systems (Hu et al., 2016; Yang and Ergan, 2017; Hu et al., 2018) and the building handover process 
(East et al., 2013; Cavka et al., 2015; Mayo and Issa, 2016; Cavka et al., 2017; Thabet and Lucas, 2017). Only one article was found that focused on creating a generic set of information requirements for a successful information exchange process (Farghaly et al., 2018). Other authors in this area proposed an information classification and prioritization methodology (RodriguezTrejo et al., 2017; Reza Hosseini et al., 2018). There remains a lack of holistic guidance that encapsulates all the information exchange requirements between BIMand FM systems (Matarneha et al., 2019).

\subsection{Interoperability and data exchange open standards}

Interoperability is the capability to exchange data among different software programs to enable automation and to reduce the need for manual data entry (Eastman et al., 2011). Because of the wide range of BIM and FM platforms, interoperability between these platforms remains one of the key challenges in using BIM in FM practice (Kasprzak and Dubler, 2012; Kassem et al., 2015; Leite et al., 2016; Nicał and Wody $\square$ nskib, 2016; Pärn et al., 2017; Gao and Pishdad-Bozorgi, 2019; Matarneha et al., 2019). There have been various recent attempts to improve interoperability by introducing different universal data standards such as the IFC and XML schemas and structured specifications such as COBie (Azhar et al., 2012; Yalcinkaya and Singh, 2019). Many countries and organizations have adopted the use of open BIMstandards and data specifications in their project handover and O\&M phase. For instance, the UK Government adopted COBie as the data exchange schema to support its BIM Level - two strategies (Kassem et al., 2015). However, these efforts represent only the first step in streamlining information flow throughout the building lifecycle. There are compelling reasons for moving forward with more pragmatic strategies to implement BIM in FM practice, but many stumbling blocks remain. One of these is the narrow use of open standards to identify the information required for FM (Patacas et al., 2015). Currently, the industry is more than ever aware of the need to remove these impediments to FM information requirements, data exchange and interoperability to extend BIM implementation to the O\&M phase. However, problems related to BIM-enabled data exchange using open standards currently remain to be resolved (Cavka et al., 2017).

Recent research first focused on interoperability and data exchange to assess BIM open standards and data specifications using a case study approach (Patacas et al., 2015; Borhani et al., 2017; Pishdad-Bozorgi et al., 2018), then BIM open data specifications (COBie) were tested in the building handover process (East et al., 2013; Thabet et al., 2016; Yalcinkaya and Singh, 2019). Finally, BIM open standards (IFC) were used to capture and exchange facility data using different technologies such as a barcode system, digital sensors and augmented reality (Lin et al., 2014; Lee et al., 2016; Shalabi and Turkan, 2017). Background research showed that the process of transferring data from BIM data models to FM systems was not a straightforward process because 
software interoperability remained a substantial challenge (Nicał and Wody $\square$ nskib, 2016; Gao and Pishdad-Bozorgi, 2019; Matarneha et al., 2019). Furthermore, the literature showed that the gap between BIM and FM systems in terms of data exchange and interoperability still existed. Bridging this gap will require more research to provide a standardized processes and best practices method for seamless data exchange between BIM and FM systems. Our study summarizes the outcomes of research to identify the current gaps in interoperability and data exchange between BIM and FM platforms and proposes a conceptual interoperability framework for seamless data exchange between BIM and FM systems.

\section{Research Methods}

The main purpose of this research was to tackle the challenge of improving the current information exchange process between BIM and FM systems. To achieve this aim, we used a mixed method approach to identify the information exchange requirements:

- an extensive review of related literature to identify the current state of BIM implementation in FM with focus on the information exchange process between BIM and FM systems;

- a questionnaire survey distributed to BIM practitioners in the UK with the goal of understanding the current state of facilities information management in BIM-based projects and to identify information exchange methods, tools and challenges; and

- two focus-group workshops facilitated by the British Institute of Facilities Management (BIFM) for the purpose of validating the developed theoretical framework of information exchange between BIM and FM systems as shown in Figure 1. 


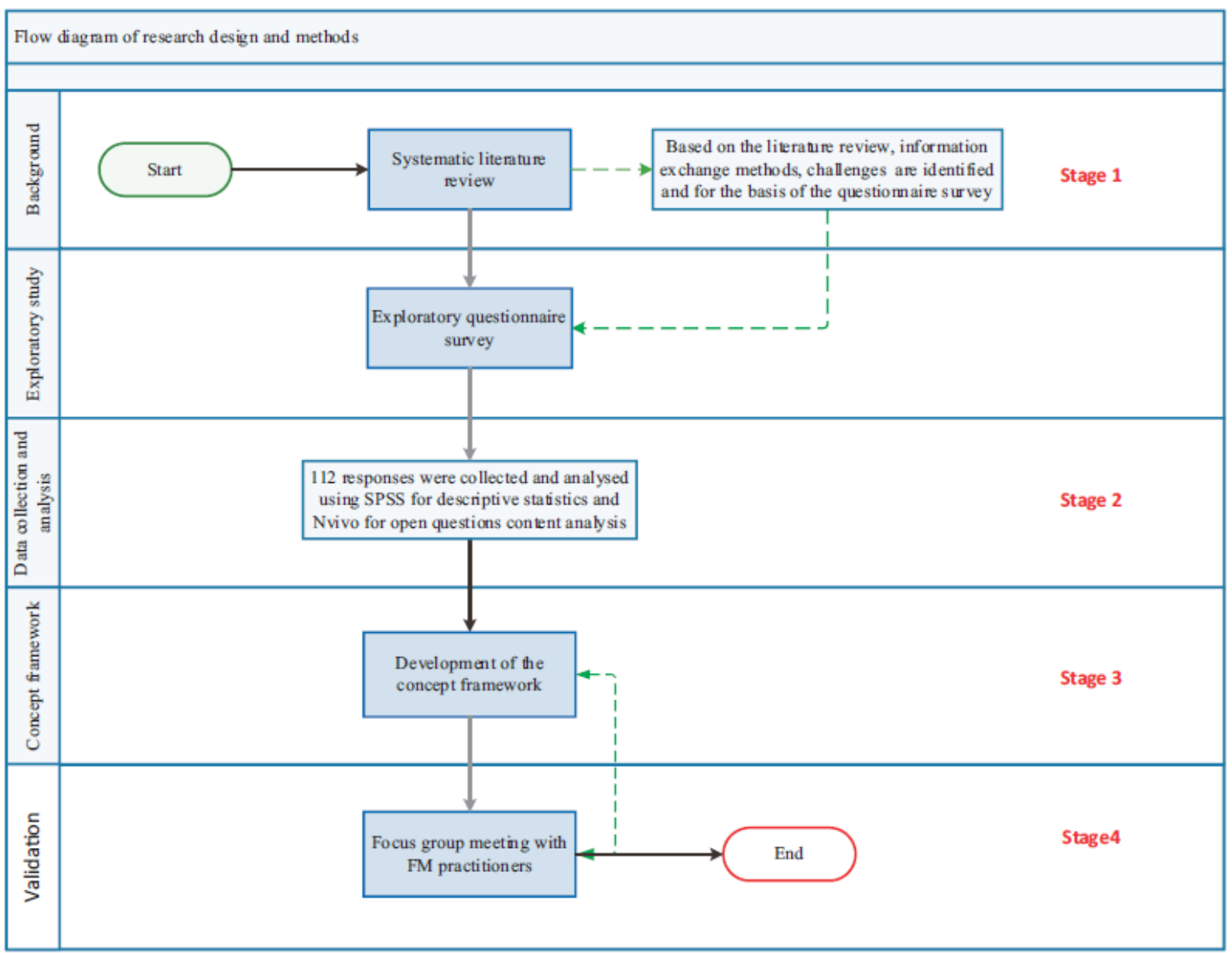

Figure 1. Research design and methods

A total of $112 \mathrm{BIM}$ practitioners completed the on-line questionnaire survey and $12 \mathrm{FM}$ practitioners participated in the focus groups.

\section{Research Results}

While our overall intention in data collection was to tackle the challenges in the current information exchange process between BIM and FM systems, our views on the importance of having a seamless information exchange process between BIM and FM systems were collated. The survey questions were exploratory in nature to generate general understanding using closed questions to identify information exchange methods, challenges and requirements. However, BIM professionals who used/or are using BIM for FM were given the opportunity to add lessons learned from their experience using an open questions. Participants were selected based on their experience in using BIM in their construction projects and their knowledge about BIM benefits for FM. The on-line questionnaire was prepared using the SMARTSurvey service and posted to related BIFM and LinkedIn professional groups such as: BIM for FM, BSIGroup, BIM Group and BIMTask Group.

The two focus group meetings were conducted with 12 FM practitioners. The aim of the first focus group was to verify the proposed information exchange requirements proposed in the primary conceptual framework, while the second focus group validated the overall developed framework 
of information exchange between BIM and FM systems. Both focus group meetings were analyzed using content analysis and Nvivo software.

\subsection{Questionnaire results}

Based on an extensive literature review, a series of questions under four themes was used in a questionnaire to collect perspectives from BIM practitioners to understand the state of information exchange between BIM and FM systems. The questionnaire was available online from January 19th, 2018 until March 31st, 2018 and 112 responses were collected. Responses were analyzed using SPSS for the descriptive statistics and Nvivo for the analysis of the qualitative open questions responses; results are presented in the following sub-sections.

4.1.1 Demographic distribution Practitioners in the construction industry in the UK were the main respondents to our questionnaire. Among the 112 participants, contractor and FM organizations were the greatest contributors with 26 per cent, followed by BIM consultants, technical engineers and architects with 21, 12 and 5 per cent, respectively. At the time of the questionnaire, 59 per cent of the respondents had been working in the construction industry for more than 10 years. The majority ( 81 per cent) had never worked on any project where BIM was used to support FM operations, but they are aware of BIM capabilities to support FM practice; only 19 per cent of the total had worked on at least one project where BIM was used to support FM. However, all respondents used BIM in different phases of the project lifecycle and were aware of BIM capabilities for FM. Participants were asked if they had knowledge about BIM capabilities for supporting facilities management practice, and all those who answered "NO" were disqualified from participating in the questionnaire survey.

\subsubsection{Building information modelling application areas in facilities information management..}

As this study focused on leveraging BIM in facilities information management, the respondents were requested to choose potential application areas that BIM, with its capability as a data conduit, could bring value to. A substantial number of responses strongly agreed that BIM could enhance building handover processes ( 86 per cent), support facilities systems (67 per cent) and facilitate creation of a registry of digital assets (62 per cent) as shown in Figure 2. This is an important finding because it demonstrated a general understanding that BIM was capable of acting as a data 
conduit to capture, collect and retrieve all information about a facility and its components during its lifecycle.

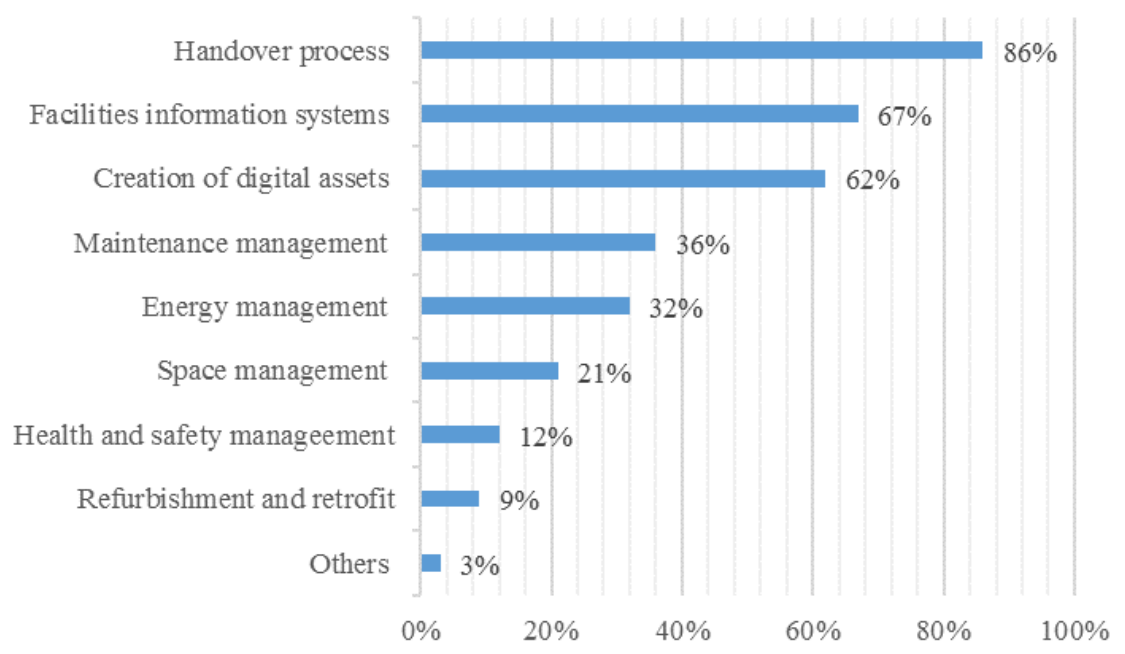

Figure 2. Potential building information modelling application areas

\subsubsection{Challenges and implications}

When BIM is used to support facilities information management, facility information can be captured, collected and retrieved throughout the building lifecycle and then used in a more automated and efficient way to support FM systems. However, some challenges still exist in using BIM as a database to support facilities information management. Among the respondents, 74 per cent agreed that poor interoperability between BIM and FM systems was a key challenge hindering BIM implementation in facilities information management. This was followed by the lack of a clear, standardized information exchange process (55 per cent) and the lack of clear information requirements (49 per cent) for BIM models to support facilities information management (Figure $3)$.

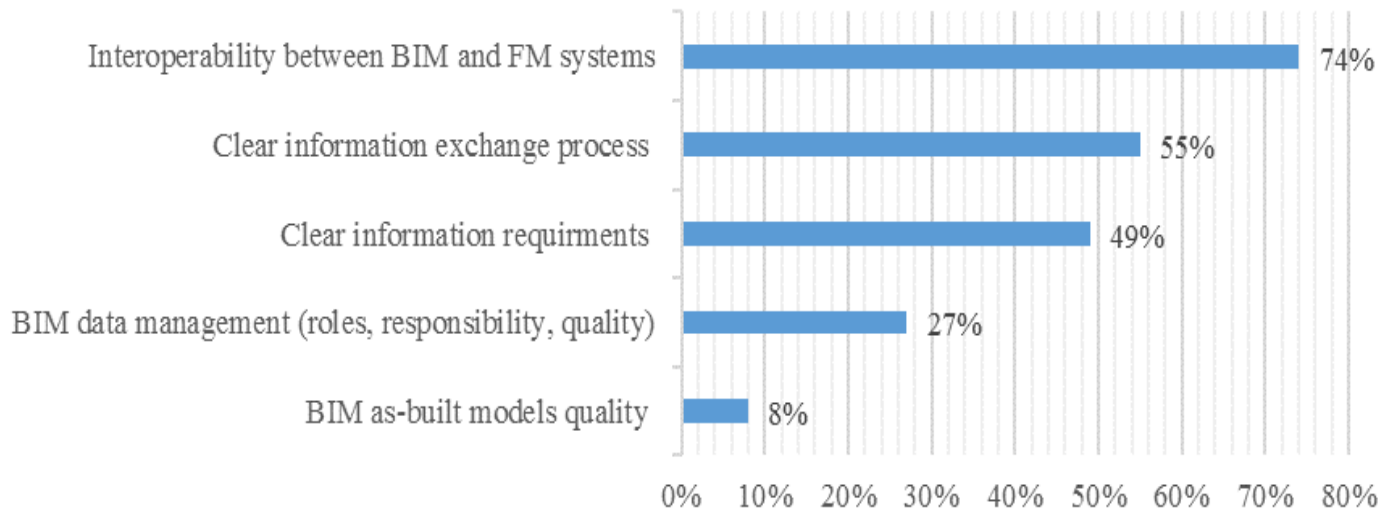

Figure 3. Concerns of implementing BIM in facilities information management practice 
4.1.4 The current state of handover processes for building information modelling-based projects. The building handover process is critical to provide owners and facility managers with all information about the facility and its components. To understand how information is delivered to owners and facility managers in a BIM-based project environment, survey takers were asked to select the deliverables they were required to provide at the building handover stage. As shown in Figure 4, the results indicated that the most frequent response was electronic copies in the form of pdf documents and CAD drawings ( 94 per cent), followed by native, as-built BIM models (91 per cent). With the adoption of BIM in construction projects, the need for non-geometric information delivery in the form of COBie.

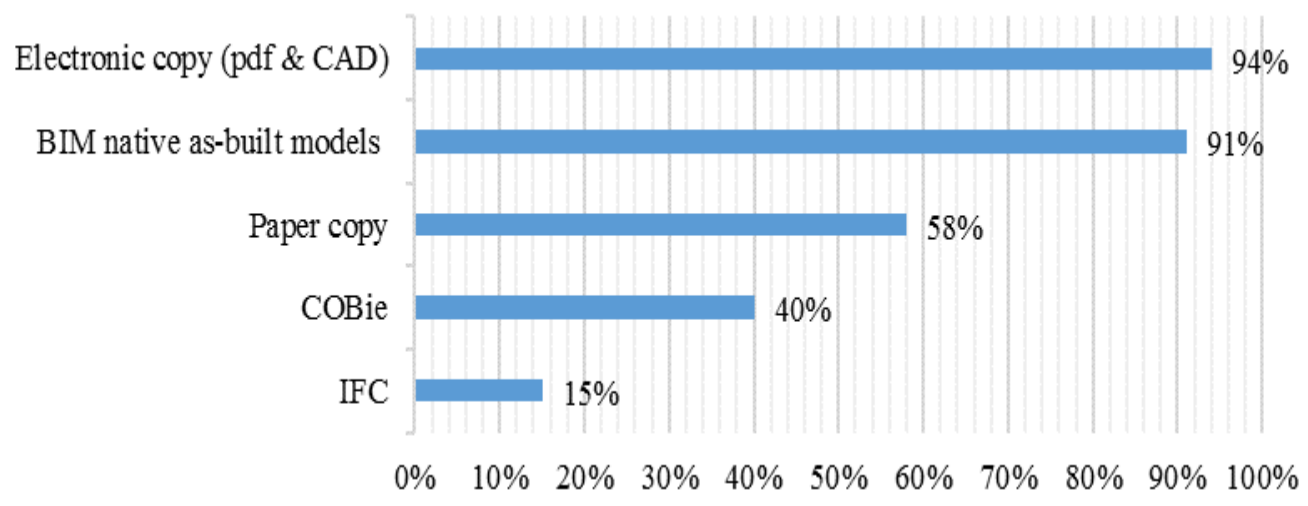

Figure 4. Handover deliverables for building information modelling- based projects

\subsubsection{Information exchange methods between building information modelling and FM systems.}

A clear information exchange process is integral to a unified source of facility information that is collected during the different phases of the construction project. Respondents who were using BIM for FM (19 per cent) were asked to select the information exchange method they used to transfer information between BIM and FM systems. Figure 5 shows that about one-third of the respondents (32 per cent) said they did not know because they were still working on BIM models and had not reached the stage of transferring data to FM systems at the time of the survey. Among the other responses, 29 per cent of participants used manual data entry, while 24 per cent used COBie spreadsheets as tools to transfer facility information from BIM models to FM systems. Meanwhile, 9 per cent of the respondents used a middleware layer and 5 per cent used IFC files to transfer information between BIM and FM systems. Respondents were asked whether they agreed that BIM models included all required facilities information: 89 per cent disagreed, 9 per cent neither agreed nor disagreed and 2 per cent said that BIM did include all required facilities information. Respondents were asked further to list the information that was still required and could not be 
included in BIM models. Most said that information related to maintenance and spare parts was usually not included in BIM models; and, even if there were a process for including this type of information, the existing COBie add-in applications do not support the generation of such data. Other respondents noted that the manufacturing information was usually not included in as-built BIM models, as manufacturers did not provide objects for BIM inclusion. Survey takers were asked to select other required data sources for facilities information management and the majority of respondents stated that the spares log and the manufacturers' product data sheets were the most wanted external data sources at 92 and 86 per cent, respectively (Figure 6).

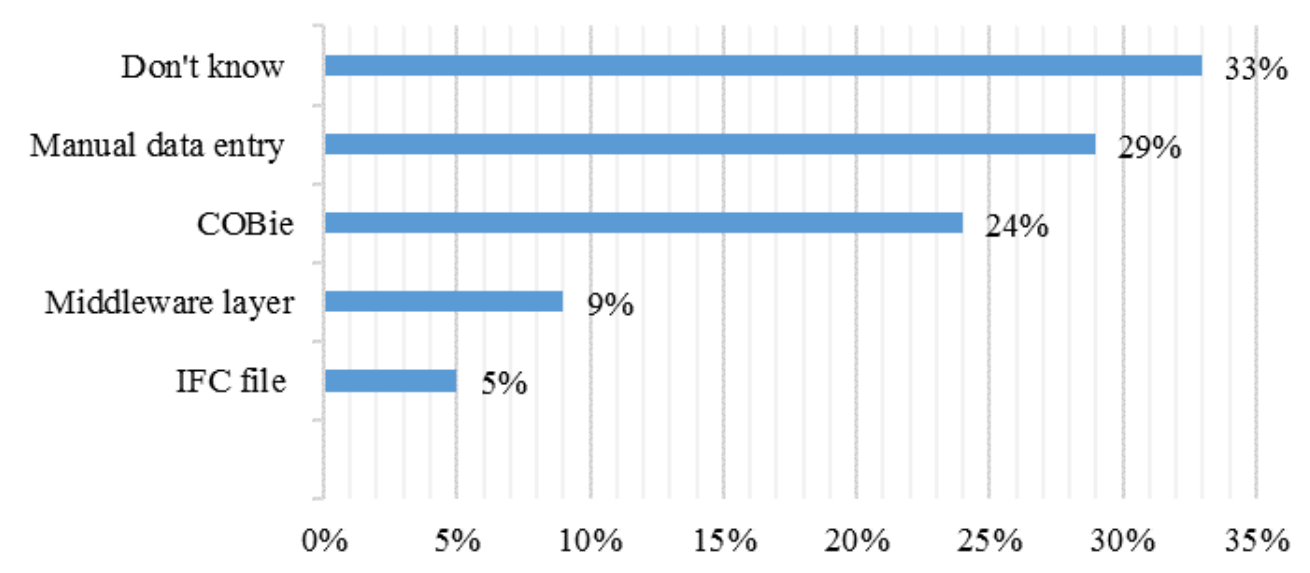

Figure 5. Information exchange methods between building information modelling and facilities management systems

\section{Discussion}

Data analysis results confirmed the value placed by industry practitioners on the necessity of having a standardized information exchange process between BIM and FM systems and how specific asset information requirements are needed to reduce the redundancy of generating BIM outputs that do not match the FM system inputs. Moreover, questionnaire results revealed that COBie add-in applications do not generate a full, rich COBie spreadsheet and require manual data entries for maintenance-related data. For example, the COBie toolkit for Revit can generate 10 sheets of the required 18 sheets, but the most important data related to asset maintenance are not included, as this COBie add-in does not generate Spare, Resource and Job sheets. Moreover, the questionnaire results revealed that in the most current practice, manufacturers are not ready to provide objects for BIM inclusion, which means that BIM as-built models do not include the manufacturers' product information, and FM teams have to collect this type of information from various sources. Building such a database by individual keystroking data entry is costly and rarely achievable. There should be an efficient process for manufacturers, suppliers and vendors to automatically provide the required data to be combined with BIM data into FM systems at 
minimal cost. With potentially hundreds of kinds of O\&M data from building systems, transforming FM practices involves creating a seamless data exchange process and converting the process into a standard. Based on the questionnaire results, we concluded that in the most current practice, BIM data generated in form of COBie spread sheet is not sufficient to support FM systems; manual data entry is still required to enter manually the information related to equipment manufacturing details (such as spares, warranties details, installing date, expected life, etc.). Accordingly, we proposed a conceptual framework that combines BIM data with other external data sources such as spares submittal logs and product data sheets to generate a rich database that includes all required facilities information. The proposed framework suggests to collect from different sources and then store the collected data in external database that will be used for further data manipulation to generate COBie spreadsheets that include manufacturer information extracted from product data sheets and spare parts log submittals.

\section{Validating the conceptual framework}

Two focus group meetings were conducted with FM practitioners working in different organizations in the UK. The 12 FM practitioners who participated in the focus group meetings included a mix of individuals working in maintenance management, healthcare FM and total FM organizations. The participants filled various roles in their departments: facility managers, project managers, directors and technicians (Table I).

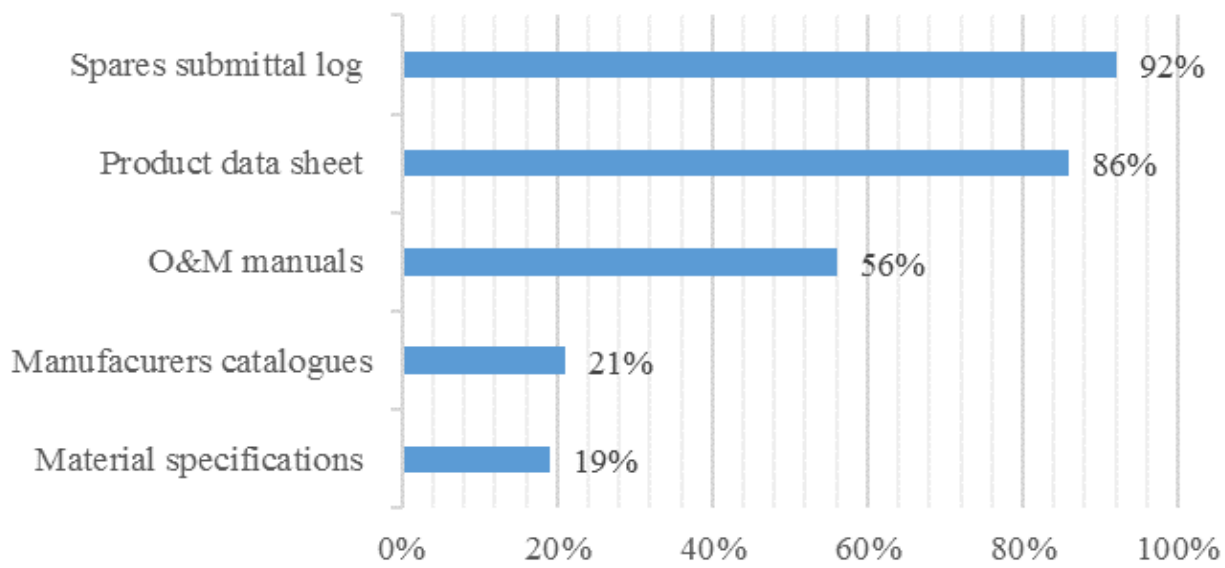

Figure 6. The required information that was not included in building information modelling models. 
Table I. BIM practitioners' background

\begin{tabular}{llrr}
\hline Variable & Scale/Category & No. & (\%) \\
\hline Work experience (years) & $1-5$ & 17 & 15 \\
& $6-10$ & 29 & 26 \\
& $11-15$ & 36 & 32 \\
& $16-20$ & 19 & 17 \\
Organization type & $>20$ & 11 & 10 \\
& Property Development & 3 & 3 \\
& Architect & 6 & 5 \\
& Engineering (technical, electrical, civil) & 13 & 12 \\
& BIM Consultant & 23 & 21 \\
& Contractor (general) & 29 & 26 \\
& Contractor (specialty) & 5 & 4 \\
& Facilities/Asset Manager & 29 & 26 \\
& Manufacturer & 3 & 3 \\
Number of projects (BIM for FM) & Other & 1 & 1 \\
& 0 & 91 & 81 \\
& $1-5$ & 21 & 19 \\
& $6-10$ & 0 & 0 \\
& $>10$ & 0 & 0 \\
\hline
\end{tabular}

The aim of the first meeting was to validate the information exchange requirements and identify information needs and sources. A list of BIM information outputs in the form of COBie spreadsheet which was generated from as-built BIM model of COBie challenge project provided online by COBie Challenge Group was distributed to participants to evaluate information exchange requirements sufficiency. Several questions related to the identification of information exchange requirements were discussed to enable interactions among multiple participants, and the findings resulted in the identification and addition of two new data sources. The first source was the industry standard, SFG20, which included maintenance schedules, and the second source was data from the manufacturers and suppliers. The meeting participants concluded that there was a need for external data sources that are not included in as-built BIM models and/or COBie data spreadsheets. Based on the results of the focus group meeting, we developed further our framework to combine different data sources extracted from the industry standards (SFG20) and from manufacturers and suppliers through a web-based interface with as-built BIM model data to provide a single comprehensive data source. Figure 7 shows the developed framework for the information exchange process between various data sources including BIM models and various FM systems. 


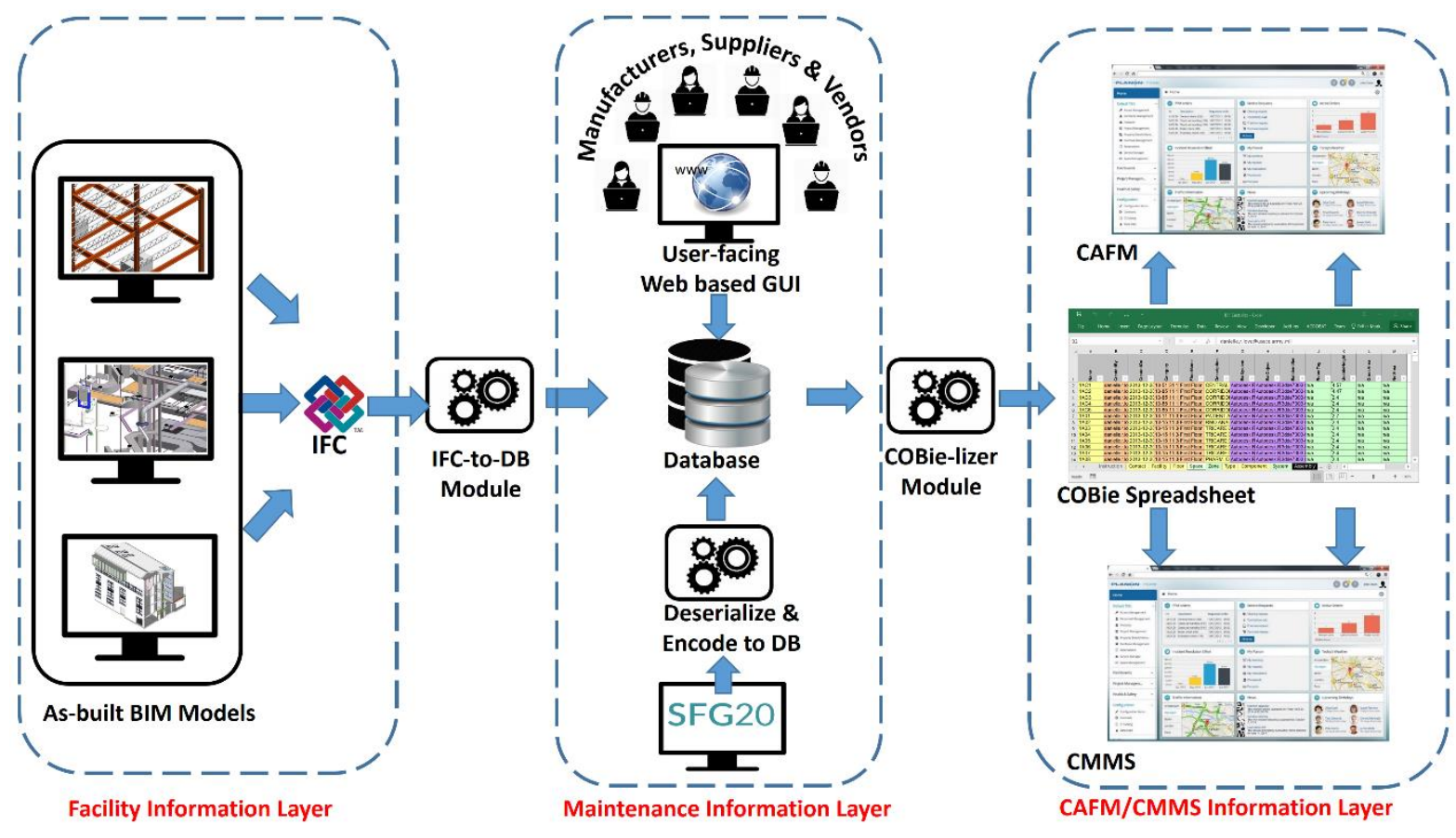

Figure 7. Information exchange framework for seamless data exchange between building information modelling and facilities management systems

The proposed framework consists of three major layers as detailed below:

(1) Facility information layer: At this layer, facility data are inputted and captured at different phases and stored in as-built BIM models. The as-built BIM models include a huge amount of geometric and non-geometric data about the facility equipment and components. These data are then transferred to the external database via IFC using the IFC-to-DB module. The basis of an IFC is to generate a solo model schema supporting information exchange between different software tools. This can viewed by different members during the project lifecycle in a different way based on their information requirements. These views are known as the Model View Definition (MVD). One of these views is the FM handover view known as COBie. The recommended view in our 
proposed framework is the IFC2 $\times 3$ Extended FM Handover View as a plain text as shown in Figure 8 .

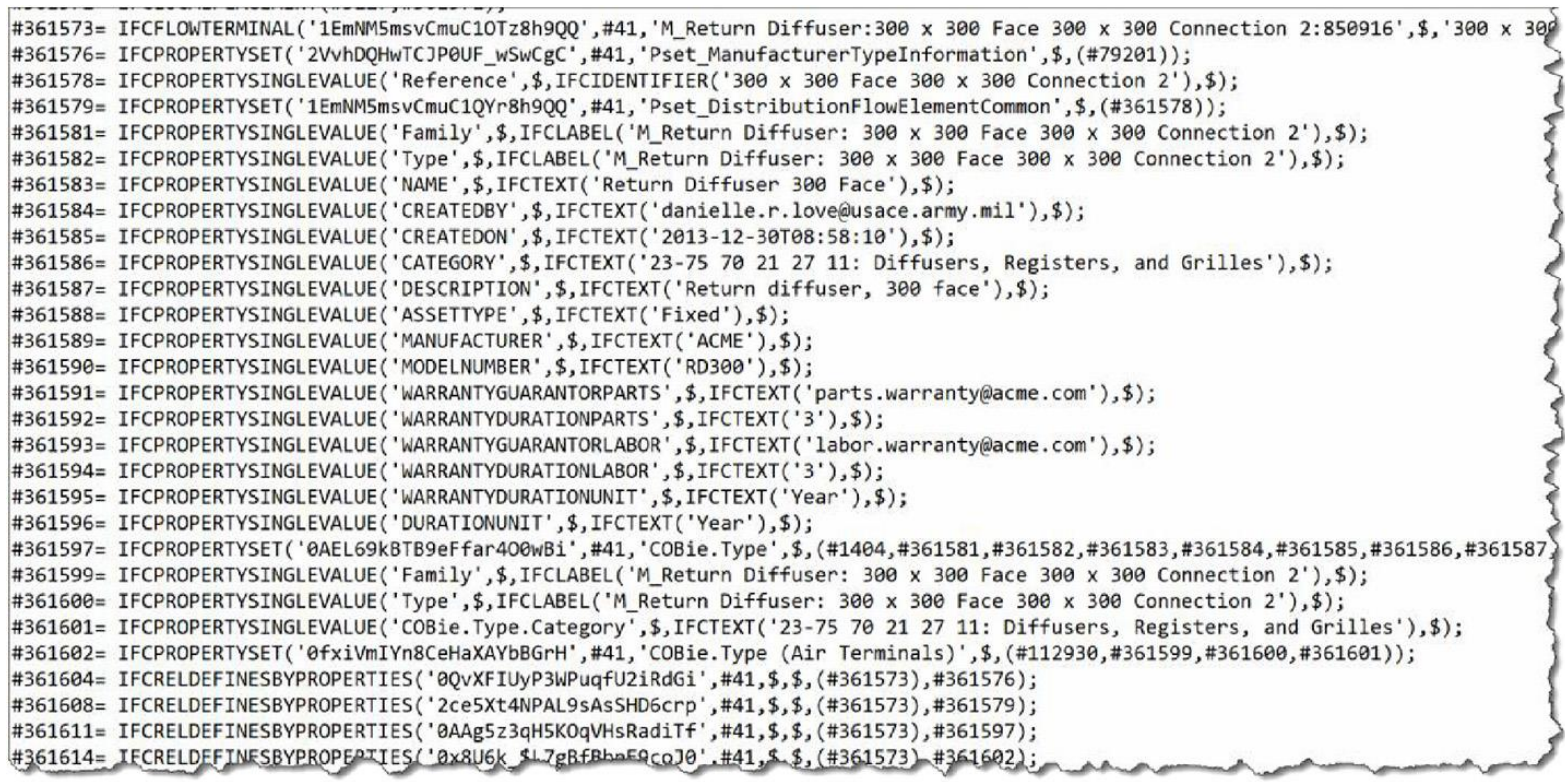

Figure 8. IFC2 x 3 extended FM handover view

(2) Maintenance information layer: Some required data related to maintenance are not included in as-built BIM models (such as preventive maintenance tasks, frequencies and durations) and as such could not be generated automatically using COBie add-ins. At this layer, this type of data is collected from different sources, namely, the industry standards (SFG20) and the proposed userfacing web-based system. The SFG20 can be available in different formats (PDF and XML formats). In the proposed framework, SFG20 XML as shown in Figure 9 is exported to the external databases for further data manipulation to extract preventive maintenance schedules, legislation requirements and critical assets information that are needed to support FM systems and can be included in COBie spreadsheet in job, resource, issue and document sheets.

All data collected at this layer will be stored in the same external database for further data manipulation. In the proposed framework, we proposed a web-based graphical user interface (wGUI) to enable manufacturers, suppliers and vendors enter products data related to O\&M and store these data in the external smart database as shown in Figure 10. The user selects a building type by typing its name on the window and loads the selected type. When the selected type is loaded, type specifications, manufacturer information, guarantee and warranty information get populated. The user then edits information and stores on the same external database. The addition of product information will provide the missing information that usually is ignored during the preparation of BIM as-built models and will enable to produce a rich COBie sheet that includes all required O\&M information. 


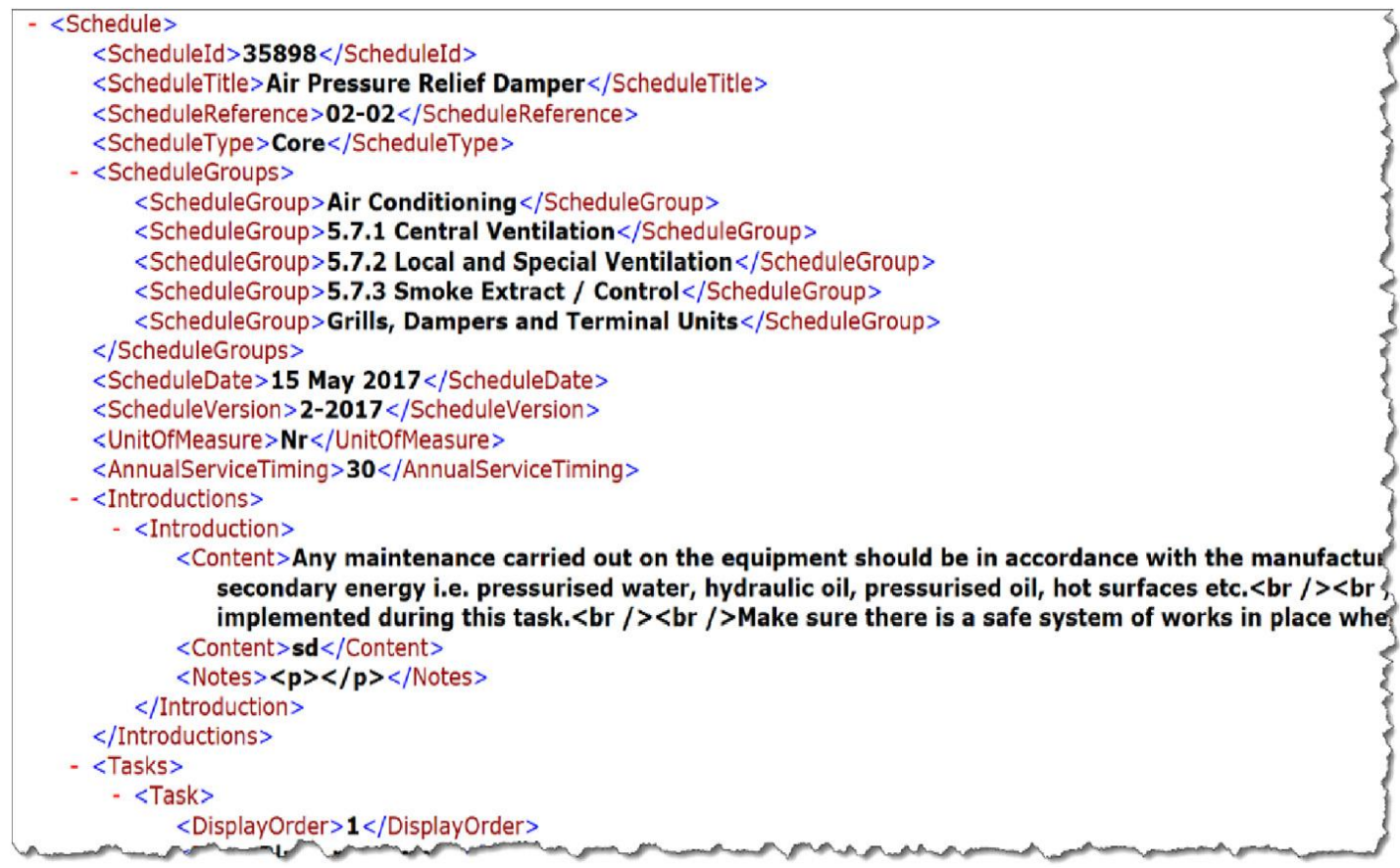

Figure 9. SFG20XML

(3) $C M M S / C A F M$ information layer: At this layer, a rich COBie spreadsheet is generated from the different data sources for FM using a 'COBie-lizer' module. Where COBie existing add-ins application have their own limitation in generating ten sheets only, COBie-lizer module has the capability of developing relationship mapping between the external database and COBie sheet schema to generate a rich COBie spreadsheet that includes all required O\&M information as shown in Figure 11.

After developing the information exchange framework, we conducted the second focus group meeting to present and validate the developed framework. Participants were asked several questions to open a discussion and stimulate interactions among participants to evaluate and validate the presented framework (Table II).

Table II. Demographic information about focus groups

\begin{tabular}{|c|c|c|c|c|c|}
\hline Code & Position & $\begin{array}{c}\text { Experience } \\
\text { (years) }\end{array}$ & Code & Position & $\begin{array}{l}\text { Experience } \\
\text { (years) }\end{array}$ \\
\hline A1 & Director of FM company & $16-20$ & B1 & Facility manager & $11-15$ \\
\hline A2 & Operations director & $16-20$ & B2 & Head of maintenance & $16-20$ \\
\hline A3 & Estate manager & $11-15$ & B3 & Project manager & $11-15$ \\
\hline A4 & Maintenance manager & $>20$ & B4 & Deputy estates and facilities manager & $16-20$ \\
\hline \multirow[t]{3}{*}{ A5 } & Maintenance technician & $16-20$ & B5 & Site Facilities Manager & $5-10$ \\
\hline & & & B6 & Facility manager & $16-20$ \\
\hline & & & B7 & Estates Manager & $>20$ \\
\hline
\end{tabular}

In conclusion, all participants agreed that combining BIM data with other data sources such as SFG20 and manufacturers' information will facilitate automated mobilization of assets registry 
and maintenance schedules in FM systems. Moreover, all the participants felt that the framework we developed could provide comprehensive, accurate information about the facility and its components from a single source which would improve the facilities information management practice. The only two things participants would add at this stage were a method for identifying data outputs that match FM system inputs and a way to define naming/coding systems for facility component to insure accurate data import from COBie spreadsheets into FM systems.

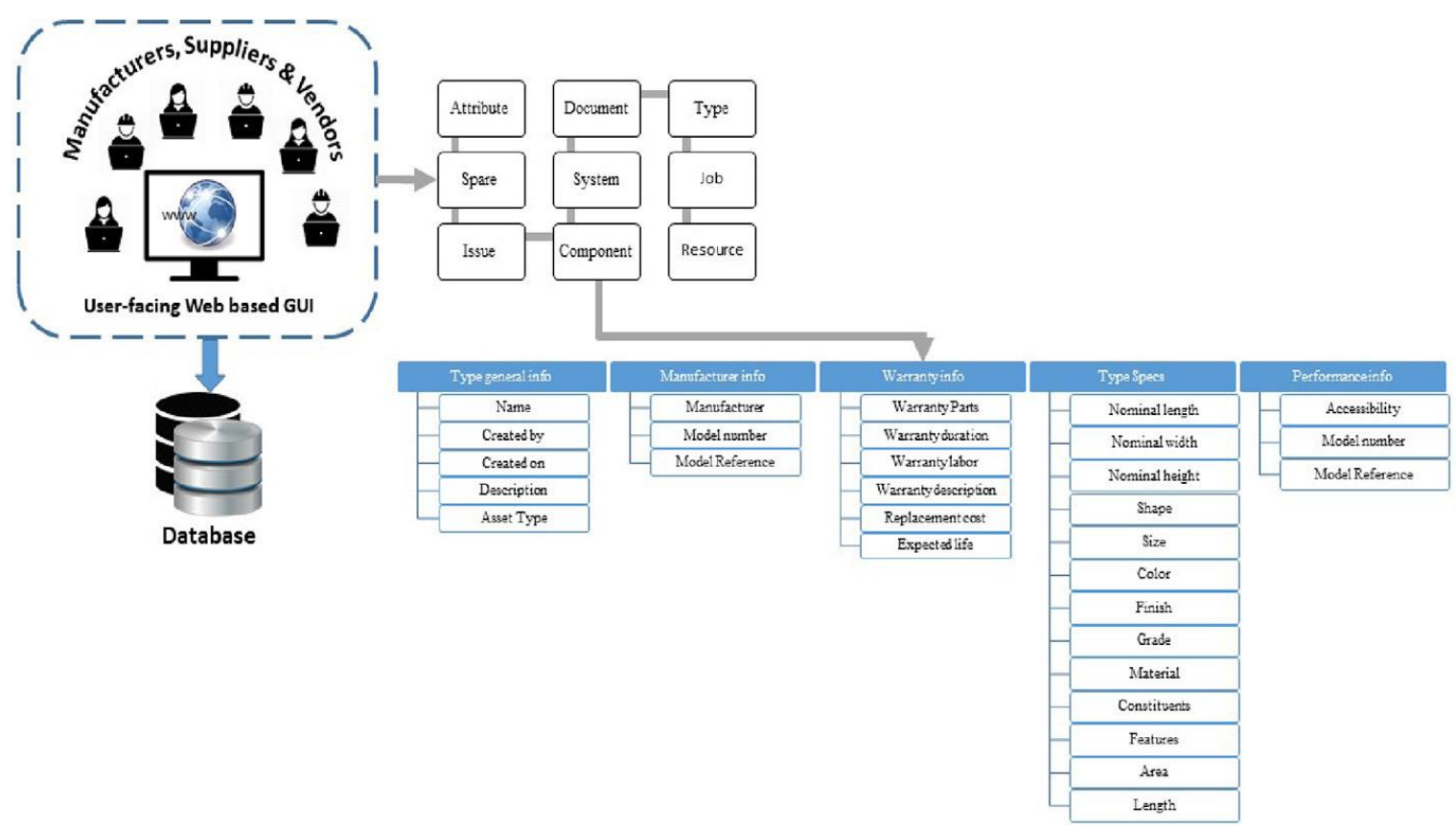

Figure 10. Web-based user interface information requirements accessibility 

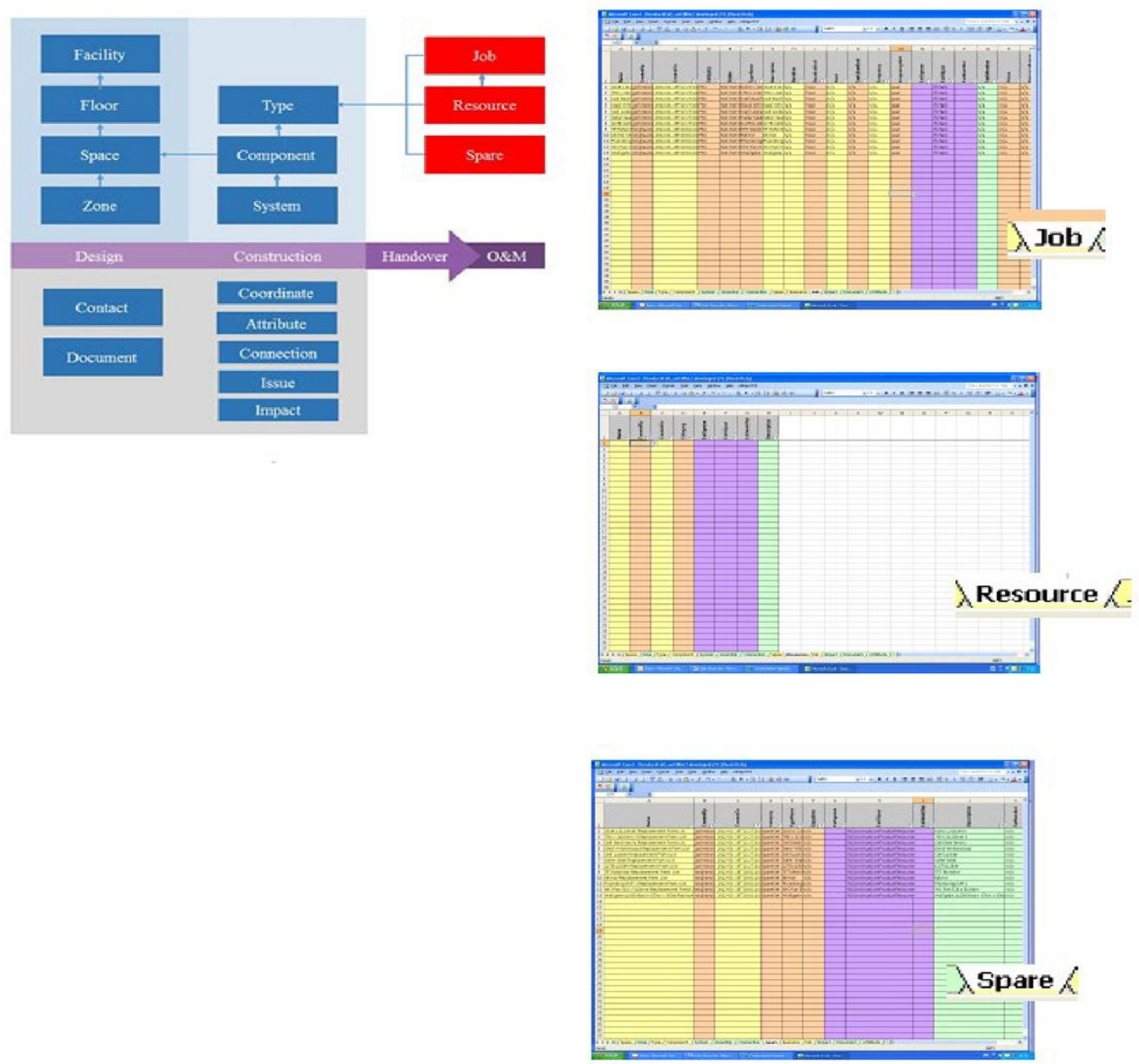

Figure 11. Data outputs included in COBie spreadsheet generated by COBie-lizer

\section{Conclusions and recommendations}

FM teams depend on multiple information systems to efficiently operate and maintain buildings. Current FM systems lack interoperability capabilities, which results in poor data management. One critical measure of building operations and maintenance is data accuracy and availability; however, capturing, storing and exchanging data within a large building is cumbersome and requires standardized processes. In this research, we investigated the current methods and tools for pushing data out of BIM models into FM systems, and our data analysis confirmed the importance of having a standardized information exchange process between BIM and FM systems. The results also revealed the need for other data sources to provide data that is not included in as-built BIM models and/or COBie spreadsheets such as maintenance data. Based on these results, we proposed a framework for a seamless information exchange between various data sources including BIM models and FM systems using an open-data format to overcome interoperability problems. The 
proposed framework works on three different levels. At the first level, data are extracted from BIM models to the external database using the open standard schema IFC. Data are then manipulated to identify the required FM information. At the second level, the required information related to maintenance schedules is extracted from two sources:

(1) the industry standards (SGF20); and

(2) the proposed web-based interface that allows different stakeholders to enter maintenance data directly into the same external database.

At the third level, data from BIM models and data collected from various sources are presented as a COBie spreadsheet using the COBie-lizer module; then data are imported from the COBie spreadsheet into CAFM/CMMS software. Connecting multiple data streams into one external database provides a seamless data flow. This would guarantee comprehensive yet specific data outputs for FM systems inputs. Having a seamless data flow that collects data automatically from different sources will improve the data exchange process and reduce the time and effort needed to enter data manually into FM systems. Moreover, this will provide FM teams with the required data about building equipment and components that will allow them to respond to various maintenance problems more efficiently. Our research findings were validated in terms of the sufficiency of the proposed framework to respond to FM information needs and to evaluate the representativeness of the identified information sources as shown in Table III.

Table III. Focus group questions and discussion

\begin{tabular}{|c|c|c|c|c|}
\hline Question & Yes & No & Unsure & Comment \\
\hline $\begin{array}{l}\text { Based on what we presented today, do you think that } \\
\text { combining BIM data, industry standards and } \\
\text { manufactures/suppliers product data will facilitate } \\
\text { automated mobilisation of asset registers and } \\
\text { maintenance schedules in CAFM/CMMS? }\end{array}$ & 7 & 0 & 0 & \\
\hline $\begin{array}{l}\text { Based on what we presented today, do you think that } \\
\text { combining BIM data, industry standards and } \\
\text { manufactures/supplier products data will improve } \\
\text { the quality and accuracy of asset information and } \\
\text { accordingly enhance the facilities information } \\
\text { management practice? }\end{array}$ & 5 & 0 & 2 & $\begin{array}{l}\text { It depends on the data accuracy of } \\
\text { BIM as-built models }\end{array}$ \\
\hline $\begin{array}{l}\text { Based on what we presented today, do you think that } \\
\text { the proposed framework is sufficiently responsive to } \\
\text { facilities management systems (CAFM/CMMS) } \\
\text { information needs? }\end{array}$ & 7 & 0 & 0 & \\
\hline $\begin{array}{l}\text { Based on what we have presented today, in your } \\
\text { opinion, what is the most important issue that you } \\
\text { would like to highlight to enhance the proposed } \\
\text { conceptual framework? }\end{array}$ & & & & $\begin{array}{l}\text { To identify FM systems } \\
\text { information requirements, } \\
\text { To define naming/coding system } \\
\text { at early stage to facilities the } \\
\text { information import process into } \\
\text { FM systems }\end{array}$ \\
\hline
\end{tabular}


This validation was accomplished through focus group meetings in which we worked with 12 experienced FM practitioners from different FM organizations. The outcomes of the analytical exploratory study in this research can be claimed as a knowledge contribution for the following reasons:

- The majority of the exploratory studies conducted in this area focused on examining broadly BIM implementation in FM, while the exploratory study in this research focused on exploring the current BIM state in FM with focus on information exchange process and interoperability between BIM and FM systems.

- The outcomes of this exploratory study shed the light on current challenges facing information exchange process between BIM and FM systems reported by BIM experts who used BIM to support FM in real practice.

These rich insights which were generated from participant's experience in the same filed contribute to better understanding of the current challenges facing BIM implementation in FM and verify the necessity to develop pragmatic solutions to overcome these challenges. Furthermore, this research contributes to the body of knowledge by proposing a novel framework for seamless information exchange between BIM and FM systems. The proposed framework enables users to retrieve various data sources and transfer the collected data seamlessly into FM systems using an open data format to overcome interoperability issue. The illustrated framework shows how BIM-based facilities information management can retrieve data from BIM models using IFC file, industry standards for maintenance using SFG20XML and manufacturing data using the web-based graphical user interface and then generate a single source of digital data output to support FM systems input. The main practical advantages of the proposed system are:

- The proposed solution is capable to take advantage of the existing interoperability solutions created by the industry, namely, COBie and bridge the gap of the existing COBie add-in applications limitations by generating a rich COBie spreadsheet that includes all required FM systems input. Through this, manual data entry of O\&M data could be reduced dramatically.

- Information quality could be effectively improved by managing fragmented data sources and manual data entry.

- Facilities information management practice could be efficiently improved by providing a single digital source of well-identified data output for FM systems inputs.

This could solve the issue of lack of interoperability between the various FM systems and could increase data credibility.

The next stage of this study will have to implement and demonstrate the proposed framework of information exchange between BIM and FM systems using a real case study. Another area of further research would be to develop a taxonomy of specific BIM data outputs for FM systems inputs. 


\section{References}

Atkin, B. \& Brooks, A. (2009), Total Facilities Management, $3^{\text {rd }}$ ed., Blackwell publisher, Chichester, UK, (6-12).

Azhar, S., Khalfan, M. and Maqsood, T., (2012), Building information modelling (BIM): now and beyond, Australasian Journal of Construction Economics and Building, 12:5-28. Available at: http://epress.lib.uts.edu.au/journals/index.php/AJCEB/article/view/3032(accessed: Nov. 2017).

Becerik-Gerber, B., Jazizadeh, F., N.Li and Calis, G., (2012), Application areas and data requirements for BIM-enabled facilities management, Journal of construction engineering and management, 138(3):431-442

BIFM, (2013), Benchmarking: Effective Performance Management for FM, British Institute of Facilities Management, UK, available at: file:///C:/Users/pc\%20user/Downloads/3benchmarkingeffectiveperformance-management-for-fm-fmlf.pdf (accessed: Nov. 2017).

Borhani, A., Lee, H. W., Dossick, C. S. and Osburn, L., (2017), BIM to Facilities Management: Presenting a Proven Workflow for Information Exchange, Washington, International Workshop on Computing in Civil Engineering

Brodt, W., (2013), Adopt Information Exchange Standards and Harvest Benefits, Facilities Manager Journal, (40-42).

Cavka, H. B., Staub-French, S. and Poirier, E. A., (2017), Developing owner information requirements for BIM-enabled project delivery and asset management, Automation in Construction, (83):169-183

Cavka, H. B., Staub-French, S. and Pottinger, R., (2015), Evaluating the alignment of organizational and project contexts for BIM adoption: A Case Study of a Large Owner Organization, Buildings, (5):265-1300

Dias, P. and Ergan, S., (2016), The need for representing facility information with customized LOD for specific FM tasks, San Juan, Puerto Rico, Construction Research Congress, CRC 2016. American Society of Civil Engineers, (2563-2572).

East, E. W., Nisbet, N. and Liebich, T., (2013), Facility management handover model view, Journal of Computing in Civil Engineering, 27(1)

Eastman, C., Teicholz, P., Sacks, R. and Liston, K. (2011), BIM Handbook:A Guide to Building Information Modeling for Owners, Managers, Designers, Engineers and Contractors, 2nd ed., John Wiley \& Sons Inc, New York. 
Gallaher, M. P., O'Conner, A.C., Dettbarn, J.L. and Gliday, L.T., (2004), Cost analysis of inadequate interoperability in the U.S. capital facilities industry, Gaithersburg, MD.: NIST GCR 04-867, U.S. Dept. of Commerce Technology Administration, available at: https://www.wbdg.org/pdfs/NBIMSv1 p1.pdf (accessed Nov. 2017).

Ham, Y. and Golparvar-Fard, M., (2015), Mapping actual thermal properties to building elements in gbXML-based BIM for reliable building energy, Automation in Construction, (49):14-224

Hjelseth, E., (2010), Exchange of relevant information in BIM objects defined by the role- andl Life-cycle information model, Architectural Engineering and Design Management, 6(4):279-287 ISO16739, (2013). Industry foundation classes (IFC) for data sharing in the construction and facility management industries, ISBN reference: 9780580911057.

Jordani, D. A., (2010), BIM and FM: the portal to lifecycle facility management, Journal of Building Information Modeling, (6):13-16.

Kassem, M. Kelly, G., Dawood, N., Serginson, M. and Lockley, S., (2015), BIM in facilities management applications: a case study of a large university complex. Built Environment Project and Asset Management - Emerald, 5(3):261-277.

Lee, J. Lee, M., Lee, S., Oh, S., Kim, B., Nam, S. and Jang, J., (2013), Development of computerized facility maintenance management system based on reliability-centred maintenance and automated data gathering, Int. J. Control Autom. SERSC 6(1):1-12.

Lee, S. and Akin, Ö., (2011), Augmented reality-based computational fieldwork support for equipment operations and maintenance, Automation in Construction, (20):338-352.

Lee, W.-L., Tsai, M-H., Yang, C-H., Juang, J-R., and Su, J-Y. (2016), V3DM+: BIM interactive collaboration system for facility management, Visualization in Engineering 4:5

Leite, F. et al., (2016), Visualization, Information Modeling, and Simulation: Grand Challenges in the Construction Industry, Journal of Computing in Civil Engineering, 30(6).

Lin, Y.-C., Su, Y.-C. \& Chen, Y.-P., 2014. Developing Mobile BIM/2D Barcode-Based Automated Facility Management System. The Scientific World Journal.

Mayo, G. K. \& Issa, R. R. A. (2016), Nongeometric building information needs assessment for facilities management, Journal of Management in Engineering,32(3) page \#s?

Nicał, A. K. and Wodyńskib, W. (2016), Enhancing facility management through BIM 6D, Procedia Engineering, Volume 164, pp. 299-306. 
Patacas, J., Dawood, N., Vukovic, V. and Kassem, M. (2015), BIM for facilities management: evaluating BIM standards in asset register creation and service life, Journal of Information Technology in Construction (ITcon), Volume 20, pp. 313-331, available at: http://www.itcon.org/2015/20 (accessed Feb. 2018)

Pishdad-Bozorgi, P., Gao, X., Eastman, C. and Self, A. P. (2018), Planning and developing facility management-enabled building information model (FM-enabled BIM). Automation in Construction, Volume 87, pp. 22-38.

Sabol, L. (2013), "BIM technology for FM", In: P. Teicholz, ed. BIM for Facility Managers. New Jersey: John Wiley \& Sons, pp. 17-45.

Shalabi, F. and Turkan, Y. (2017), IFC BIM-based facility management approach to optimize data collection for corrective maintenance, Journal of Performance of Constructed Facilities, 31(1)

Teicholz, P. (2013), BIM for Facility Managers, New Jersey, U.S.: John Wiley \& Sons.

Thabet, W., Lucas, J. and Johnston, S. (2016), A case study for improving BIM-FM handover for a large educational institution, Construction Research Congress, Puerto Rico

Tretten, P. and Karim, R., (2014), "Enhancing the usability of maintenance data management systems", J. Qual. Maintenance Eng., 20(3), pp. 290-303 